\title{
Genetically Elevated C-Reactive Protein and Ischemic Vascular Disease
}

Zacho J, Tybjaerg-Hansen A, Jensen JS, et al.: Genetically elevated C-reactive protein and ischemic vascular disease. N Engl J Med 2008, 359:1897-1908.

Rating: $\bullet$ Of importance.

Introduction: Elevated levels of C-reactive protein (CRP) are associated with increased risk of cardiovascular disease [1,2]. Although some experimental and clinical studies suggest that high levels of exogenous CRP could impair vascular function $[3,4]$, it is not known whether CRP is truly a mediator of cardiovascular disease.

Aims: To determine whether there is a causal relationship between elevated CRP and increased cardiovascular disease.

Methods: This was a case-controlled and cross-sectional epidemiologic study of 10,276 and 31,992 persons, respectively, from a general population that included individuals who subsequently developed ischemic heart and cerebrovascular disease. Levels of high-sensitivity CRP (hs-CRP) were measured, and genotyping for four CRP polymorphisms and two apolipoprotein $\mathrm{E}$ polymorphisms was conducted.

Results: Individuals with elevated levels of hs-CRP of greater than $3 \mathrm{mg} / \mathrm{L}$ had a 1.6- and 1.3-fold increased risk for ischemic heart disease and ischemic cerebrovascular disease, respectively, compared with individuals with hs-CRP of less than $1 \mathrm{mg} / \mathrm{L}$. Individuals with hs-CRP polymorphism had a $64 \%$ increase in hs-CRP, but this was not associated with increased cardiovascular events. In contrast, individuals with apolipoprotein E polymorphism had elevated cholesterol levels and increased risk for ischemic heart disease.

Discussion: CRP polymorphisms are associated with elevated hs-CRP levels but not with increased cardiovascular events. These findings suggest that elevated hs-CRP levels from CRP polymorphisms are not related to the increased risk of cardiovascular disease.

\section{Comments}

Although this study strongly suggests that CRP is not a mediator of cardiovascular disease, it does confirm that hs-CRP is a marker of increased cardiovascular risk. However, whether hs-CRP is an independent marker of cardiovascular risk, and if so, how much it adds to traditional risk markers, still warrants further investigation.

\section{Acknowledgment}

Dr. James K. Liao is affiliated with the Vascular Medicine Research Department at the Brigham \& Women's Hospital. Correspondence should be sent to 65 Landsdowne Street, Room 275, Cambridge, MA 02139, USA. E-mail: jliao@rics.bwh.harvard.edu.

\section{Disclosure}

No potential conflict of interest relevant to this article was reported.

\section{References}

1. Ridker PM, Cushman M, Stampfer MJ, et al.: Inflammation, aspirin, and the risk of cardiovascular disease in apparently healthy men. N Engl J Med 1997, 336:973-979.

2. Ridker PM, Hennekens CH, Buring JE, Rifai N: C-reactive protein and other markers of inflammation in the prediction of cardiovascular disease in women. N Engl J Med 2000, 342:836-843.

3. Verma S, Wang CH, Li SH, et al.: A self-fulfilling prophecy: $\mathrm{C}$-reactive protein attenuates nitric oxide production and inhibits angiogenesis. Circulation 2002, 106:913-919.

4. Pepys MB, Hirschfield GM, Tennent GA, et al.: Targeting C-reactive protein for the treatment of cardiovascular disease. Nature 2006, 440:1217-1221. 